\title{
AKTIVITAS ANTIOKSIDAN FRAKSI FLAVONOID BEBAS ANDROGRAFOLID DARI HERBA SAMBILOTO(Andrographis paniculata)
}

\author{
Eka Prasasti Nur Rachmani $\left.{ }^{1,2 *}\right)$, Suwijiyo Pramono ${ }^{1)}$, Agung Endro Nugroho ${ }^{1)}$ \\ ${ }^{1)}$ Fakultas Farmasi, Universitas Gadjah Mada, Yogyakarta \\ ${ }^{2)}$ JurusanFarmasi, Fakultas Ilmu-ilmu Kesehatan, Universitas Jenderal Soedirman,Purwokerto, Jawa \\ Tengah \\ Corresponding author: ekasholehah@yahoo.com \\ 081391280002
}

\begin{abstract}
This study aims to determine the antioxidant activity of andrographolide-free flavonoid fraction (FFBA) from bitter herbs (Andrographis paniculata). FFBA is a fraction that contains flavonoids and the andrographolide compounds has been removed. The antioxidant activity of FFBA was tested using the method of reducing free radicals from DPPH (1,1-diphenyl-2-pikrilhidrazil) and using quercetin as a standard. The results showed that FFBA has antioxidant activity with strong activity with IC 50 value of $88.98 \mu \mathrm{g} / \mathrm{mL}$ while quercetin has a very strong activity with IC 50 value of $3.42 \mu \mathrm{g} / \mathrm{mL}$.
\end{abstract}

Key Words : antioxidant, Andrographis paniculata, DPPH, flavonoid

\begin{abstract}
ABSTRAK
Penelitian ini bertujuan untuk mengetahui aktivitas antioksidan pada fraksi flavonoid bebas andrografolid (FFBA) dari herba sambiloto (Andrographis paniculata). FFBA merupakan fraksi yang mengandung flavonoid dan sudah dihilangkan kandungan senyawa andrografolid. Aktivitas antioksidan FFBA diuji dengan menggunakan metode peredaman radikal bebas dari DPPH (1,1diphenyl-2-pikrilhidrazil) dengan baku pembanding kuersetin. Hasil penelitian menunjukkan bahwa FFBA memiliki aktivitas antioksidan dengan aktivitas yang kuat yaitu dengan nilai IC $_{50}$ sebesar88.98 $\mu \mathrm{g} / \mathrm{mL}$ sedangkan kuersetin memiliki aktivitas yang sangat kuat yaitu dengan nilai sebesar 3,42 $\mu \mathrm{g} / \mathrm{mL}$.
\end{abstract}

Kata kunci :antioksidan, Andrographis paniculata, DPPH, flavonoid

Eka prasasti nur rachmani dkk... 


\section{PENDAHULUAN}

Sambiloto

(Andrographis paniculata) secara turun-temurun telah dimanfaatkan untuk berbagai macam pengobatan. Sambiloto dipercaya dapat mengobati diabetes (Wahyuningrum dkk., 2016), tekanan darah tinggi, rematik, gatal-gatal, keputihan dan diuretik.

Herba sambiloto mengandung lebih dari 55 diterpenoid, 30 flavonoid, 8 asam quinat dan 4 xanton (Hossain, dkk., 2014). Jenis flavonoid yang terkandung adalah apigenin, kuersetin, 7-Ometilwogonin, luteolin, golongan flavon yang termetoksilasi serta golongan xanthon yang termetoksilasi (Hossain dkk., 2014).

Flavonoid adalah salah satu senyawa yang memiliki aktivitas antioksidan. Salah satu mekanismenya adalah flavonoid dapat mereduksi radikal bebas. Flavonoid seperti kalkon, flavon, flavonol, flavanone, dan katekin memiliki aktivitas antioksidan (Edy dkk., 2017; Markham, 1988).

Sebagian besar penyakit diawali oleh reaksi oksidasi yang berlebihan didalam tubuh. Radikal bebas merupakan molekul yang mempunyai satu atau lebih elektron tidak berpasangan dalam orbital luarnya sehingga sangat reaktif mencari pasangannya. Kejadian seperti ini menimbulkan reaksi berantai dan sel-sel tubuh mengalami kerusakan. Oleh karena itu dibutuhkan antioksidan untuk menghambat atau mencegah proses reaksi radikal bebas.

$$
\text { Penelitian sebelumnya }
$$

menunjukkan bahwa ekstrak air herba sambiloto memiliki kandungan flavonoid total sebesar 3,7\%. Fraksinasi dari ekstrak air diperoleh bahwa kandungan flavonoid tertingggi terdapat pada fraksi etil asetat yaitu sebesar 9,26\% (Rachmani ${ }^{\mathrm{a}}$ dkk, 2016). Hal ini menunjukkan bahwa ekstrak etil asetat memiliki kandungan flavonoid yang cukup tinggi. Fraksi etil asetat herba sambiloto dari ekstrak air juga memiliki aktivitas antioksidan yang cukup tinggi yaitu dinyatakan dengan nilai $\mathrm{IC}_{50}$ sebesar 402,5 $\mu \mathrm{g} / \mathrm{mL}$ (Rachmani ${ }^{\mathrm{b}} \mathrm{dkk}$, 2016).

Ekstrak etil asetat herba sambiloto memiliki kandungan andrografolid dan flavonoid (Rachmani ${ }^{\mathrm{b}}$ dkk, 2016). Penelitian ini bertujuan untuk mengetahui aktivitas antioksidan melalui metode peredaman radikal bebas dari fraksi flavonoid yang tidak mengandung andrografolid. Fraksi ini selanjutnya disebut sebagai fraksi flavonoid bebas andrografolid (FFBA).

\section{METODE PENELITIAN}

\section{Bahan Penelitian}

Bahan penelitian adalah herba sambiloto (Andrographis paniculata) yang diambil dari daerah Kulon Progo, Yogyakarta pada bulan Maret 2016. Difenilpikril Hidrazil Hidrat (DPPH) dari Sigma. Pelarut yang digunakan adalah aquades, kloroform, etil asetat, metanol, dan silika gel $60 \quad F_{254}$ from coloum dari E'Merck.

\section{Prosedur Penelitian}

\section{Penyiapan Bahan (Edy dkk., 2016)}

Tanaman sambiloto yang dipanen pada umur 3-4 bulan. Herba sambiloto yang digunakan adalah daun dan batang. Herba yang sudah dikumpulkan kemudian disortasi dan dibersihkan dengan dengan air mengalir. Pengeringan herba sambiloto dilakukan dalam oven suhu $50-60^{\circ} \mathrm{C}$. Herba sambiloto yang kering(ditandai

Eka prasasti nur rachmani dkk... 
dengan remuk ketika diremas) kemudian dibuat serbuk untuk memperbesar luas permukaan.

\section{Pembuatan fraksi flavonoid bebas andrografolid (FFBA)}

Sebanyak $300 \mathrm{mg}$ serbuk simplisia sambiloto ditimbang kemudian dilakukan perebusang dengan metode dekokta, yaitu dengan mendidihkan serbuk simplisia selama 30 menit.Waktu dihitung setelah suhu mencapai $90^{\circ} \mathrm{C}$. Filtrat hasil dekokta kemudian dikentalkan menggunakan cawan porselen di atas penangas air.

Filtrat kental herba sambiloto kemudian dipartisi berturut-turut dengan menggunakan kloroform dan etil asetat. Filtrat kental herba sambiloto ditambah kloroform kemudian dilakukan penggojogan.Setelah terbentuk dua lapisan, lapisan kloroform (bagian bawah) dipisahkan.Partisi dengan kloroform diulang tiga kali. Filtrat kloroform yang diperoleh kemudian dijadikan satu dan diuapkan hingga diperoleh fraksi kloroform.Partisi dilanjutkan dengan menambahkan pelarut etil asetat pada residu. Partisi dilakukan dengan cara yang sama seperti partisi dengan menggunakan kloroform, maka akan diperoleh fraksi etil asetat. Fraksi etil asetat yang diperoleh kemudian dihilangkan kandungan andrografolidnya dengan cara dilakukan kromatografi kolom vakum (KVC). Penentuan fraksi yang tidak mengandung andrografolid dilakukan berdasarkan kromatografi lapis tipis (KLT). Fraksi yang sudah tidak mengandung andrografolid ini selanjutnya disebut dengan fraksi flavonoid bebas andrografolid (FFBA).

\section{Penetapan Aktivitas Antioksidan}

7,88 mg DPPH serbuk ditambahkan ke volume $200 \mathrm{~mL}$ metanol untuk mendapatkan larutan DPPH 0,1 mM. Larutan DPPH harus dibuat baru. 2 $\mathrm{mL}$ larutan DPPH ditambahkan dengan 1 $\mathrm{mL}$ etanol.Campuran DPPH dan larutan FFBA dibiarkan ditempat gelap selama 30 menit.Larutan diukur dengan spektrofotometri UV-Vis pada panjang gelombang 400-800 $\mathrm{nm}$ dengan blanko metanol.

Penetapan operating time dibutuhkan antara ekstrak dan DPPH bereaksi secara optimal. Larutan DPPH dimasukkan ke dalam 8 tabung reaksi, masing-masing $2 \mathrm{~mL}$. Kemudian ditambahkan $1 \mathrm{~mL}$ FFBA dengan konsentrasi $100 \mu \mathrm{g} / \mathrm{mL}$. Setiap tabung reaksi diinkubasi di tempat gelap dengan waktu yang berbeda dalam baku 5 menit, 10 menit, 15 menit, 20 menit, 25 menit, 30 menit, 35 menit, dan 40 menit.Absorbansi sampel diukur pada panjang gelombang 515,5 $\mathrm{nm}$ dengan blanko metanol.

FFBA herba sambiloto dibuat dengan konsentrasi yang berbeda yaitu 15, 30, 60 dan 120 ppm. Setiap konsentrasi sampel diambil $1 \mathrm{~mL}$, dan ditambahkan $2 \mathrm{~mL}$ larutan DPPH.sampel yang homogen dan kemudian didiamkan selama 30 menit di tempat gelap. Pengukuran peredaman radikal bebas dilakukan pada panjang gelombang 515,5 nm.

Senyawa yang digunakan sebagai pembanding adalah kuersetin yang sudah diketahui memiliki aktivitas antioksidan. Kuersetin juga merupakan senyawa yang terkandung dalam herba sambiloto. Pengukuran peredaman radikal bebas kuersetin dilakukan dengan cara yang sama seperti FFBA.

\section{Analisis Data}

Eka prasasti nur rachmani $\mathrm{dkk} .$. 
Persen peredaman diperoleh dari rata-rata nilai absorbansi sampel. \% peredaman radikal bebas dihitung dengan menggunakan rumus :

$\%$ Peredaman $=\left(1-\frac{\text { Absorbansi sampel uji }}{\text { Absorbansi pembanding }}\right) \times 100 \%$

Kurva hubungan konsentrasi sampel vs persen penghambatan akan menghasilkan persamaan regresi sehingga dapat dihitung nilai $\mathrm{IC}_{50}$.

\section{HASIL DAN PEMBAHASAN}

Pembuatan fraksi flavonoid bebas andrografolid (FFBA)dari ekstrak air herba sambiloto dilakukan dengan metode kromatografi kolom vakum. FFBA yang diperoleh kemudian dideteksi bahwa sudah tidak mengandung andrografolid dengan metode KLT seperti pada gambar 1 .

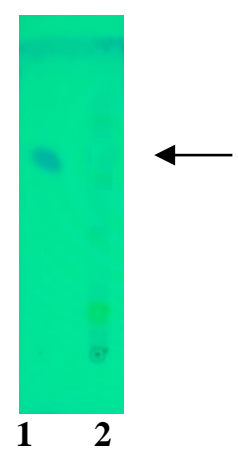

Gambar 1. Isolat andrografolid (1) dan FFBA (2). Fase diam silika dan fase gerak heksan : etil asetat (1:4). Dilihat pada $U V_{254}$. $\longleftarrow$ : Rf isolat andrografolid yaitu 0,65$)$.

Dari gambar 1 menunjukkan pengukuran DPPH.Metode DPPH dipilih bahwa eluasi andrografolid dengan fase gerak diatas diperoleh bercak andrografolid pada Rf 0,65. Pada FFBA sudah tidak mengandung andrografolid. Hal ini dibuktikan bahwa pada FFBA tidak terdapat berdcak andrografolid pada Rf yang sama,

Aktivitas peredaman radikal bebas diukur dengan menggunakan metode karena mudah, cepat, peka dan memerlukan sedikit sampel.Sebelum melakukan pengukuran absorbansi sampel, dilakukan terlebih dahulu pengukuran panjang gelombang maksimal DPPH. Panjang gelombang maksimum DPPH diperoleh pada 515,5 nm.Hasil pengukuran panjang gelombang maksimal dapat dilihat pada gambar 2 .

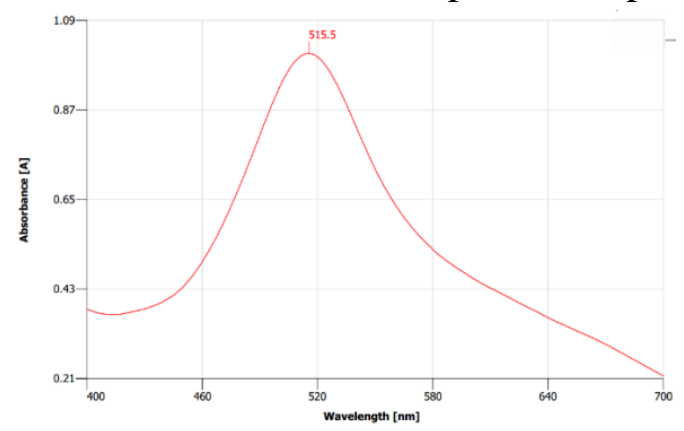

Gambar 2. Panjang gelombang maksimum DPPH dalam metanol

Pengukuran absorbansi aktivitas kuersetin sebagai pembanding dan sampel
FFBA dalam larutan DPPH dilakukan pada panjang gelombang $515,5 \mathrm{~nm}$.

Eka prasasti nur rachmani dkk... 
Penentuan operating time (OT) bereaksi sempurna dengan DPPH. dilakukan untuk mengetahui waktu Penentuan OT dapat dilihat pada gambar 3 pengukuran paling stabil saat sampel

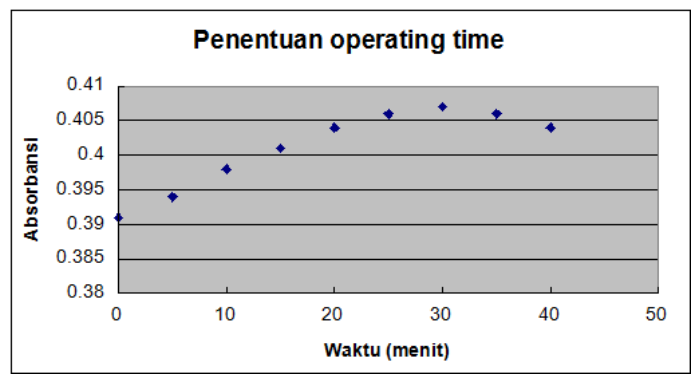

\section{Gambar 3. Penentuan operating time}

Hasil scanning OT diperoleh waktu optimal pengukuran terjadi pada menit ke-30 sehingga pengukuran absorbansi sampel dilakukan pada menit ke-30.

Pengukuran aktivitas antioksidan menggunakan blanko larutan DPPH radikal dalam metanol.Pengukuran dilakukan pada FFBA pada beberapa konsentrasi yang berbeda.Pengukuran dilakukan tiga kali pada tiap-tiap sampel pada menit ke-30.Hasil rata-rata pengukuran peredaman radikal bebas dapat dilihat pada tabel 1 .

Tabel 1. Aktivitas peredaman radikal bebas

\begin{tabular}{lcc}
\hline Senyawa & $\begin{array}{l}\text { Konsentrasi } \\
(\boldsymbol{\mu g} / \mathbf{m L})\end{array}$ & $\begin{array}{l}\text { Rata-rata } \\
\text { \% penghambatan }\end{array}$ \\
\hline Kuersetin & $\mathbf{0 , 5}$ & $\mathbf{2 1 , 7 5 6}$ \\
& 1 & 31,238 \\
& 2 & 42,116 \\
& 4 & 56,886 \\
FFBA & 6 & 68,663 \\
& $\mathbf{6 2 , 5}$ & $\mathbf{1 3 , 0 2 4}$ \\
& 125 & 25,399 \\
& 250 & 40,369 \\
& 500 & 62,226 \\
\hline
\end{tabular}

Aktivitas peredaman radikal bebas penghambatan. Grafik persen dari kuersetin dan FFBA pada tabel 1 penghambatan dapat dilihat pada gambar menunjukkan bahwa semakin besar 4. konsentrasi, semakin besar persen

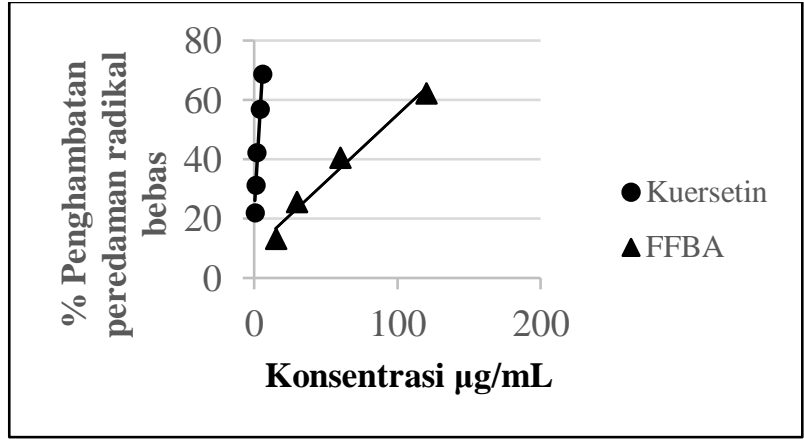

Eka prasasti nur rachmani dkk... 


\section{Gambar4. Aktivitas peredaman radikal bebas}

Grafik 4 menunjukkan hubungan antara konsentrasi dengan persen peredaman radikal bebas dari kuersetin dan FFBA dari herba sambiloto. Semakin tinggi konsentrasi, \%peredaman radikal bebas juga semakin tinggi. Konsentrasi yang kecil pada kuersetin dapat meredam radikal bebas dengan aktivitas yang tinggi. Pada FFBA membutuhkan konsentrasi yang lebih tinggi untuk dapat meredam radikal bebas.
Aktivitas antioksidan (melalui mekanisme peredaman radikal bebas) dinyatakan dengan nilai $\mathrm{IC}_{50}$. Nilai $\mathrm{IC}_{50}$ merupakan bilangan yang menunjukkan konsentrasi sampel $(\mu \mathrm{g} / \mathrm{mL})$ yang mampu menghambat proses oksidasi sebesar 50\%.Dari persamaan regresi diatas diperoleh nilai $\mathrm{IC}_{50}$ seperti terdapat pada tabel 2 berikut ini.

Tabel 2. Nilai persamaan regrasi linear dan aktivitas antioksidan dari FFBA herba sambiloto

\begin{tabular}{llcc}
\hline No & Sampel uji & Persamaan regresi & $\begin{array}{l}\text { Aktivitas } \\
\mathbf{I C}_{\mathbf{5} \mathbf{0}}(\boldsymbol{\mu g} \mathbf{g} \mathbf{m L})\end{array}$ \\
\hline 1 & Kuersetin & $\mathrm{y}=8.1774 \mathrm{x}+22.053$ & 3.42 \\
2 & $\begin{array}{l}\text { FFBA (fraksi flavonoid } \\
\text { bebas andrografolid) }\end{array}$ & $\mathrm{y}=0.4505 \mathrm{x}+9.9128$ & 88.98 \\
\hline
\end{tabular}

Aktivitas antioksidan ditetapkan dengan nilai $\mathrm{IC}_{50}$. Kuersetin memiliki aktivitas antioksidan dengan nilai $\mathrm{IC}_{50}$ sebesar 3,42 $\mu \mathrm{g} / \mathrm{mLsedangkan}$ FFBA memiliki nilai $\mathrm{IC}_{50}$ sebesar $88,98 \mu \mathrm{g} / \mathrm{mL}$.Semakin rendah nilai $\mathrm{IC}_{50}$ mengindikasikan bahwa semakin kuat aktivitas suatu senyawa ujidalam meredam adanya radikal bebas sehingga semakin tinggi aktivitas antioksidan.

Kategori penentuan kekuatan aktivitas antioksidan menurut Mardawati pada tahun 2008 menyatakan bahwa jika IC50<50 $\mu \mathrm{g} / \mathrm{mL}$ menunjukan aktivitas antioksidan yang sangat kuat. pada 50-100 $\mu \mathrm{g} / \mathrm{mL}$ menunjukkan aktivitas kuat, pada 101-150 menunjukkan aktivitas sedang, dan jika 151-200 $\mu \mathrm{g} / \mathrm{mL}$ menunjukkan aktivitas lemah.

Pengujian antioksidan pada FFBA dengan pembanding kuersetin menunjukkan bahwa kategori aktivitas antioksidan FFBA termasuk kuat yaitu sebesar 88,98 $\mu \mathrm{g} / \mathrm{mLsedangkan} \mathrm{kategori}$ aktivitas antioksidan kuersetin termasuk sangat kuat sebesar $3,42 \mu \mathrm{g} / \mathrm{mL}$. FFBA merupakan fraksi yang mengandung flavonoid yang dominan. Hal ini menunjukkan bahwa flavonoid dari herba sambiloto memiliki aktivitas antioksidan melalui peredaman radikal bebas.

DPPH larut dalam pelarut polar misalnya metanol dan etanol. DPPH adalah radikal yang stabil dan dapat diukur intensitasnya pada panjang gelombang 515,5nm. Pencampuran radikal DPPH dengan senyawa yang dapat menyumbangkan atom hidrogen. Hal ini akan memunculkan bentuk tereduksi yang ditunjukkan dengan perubahan warna ungu menjadi kuning. Perubahan warna ini dapat diukur secara spektrofotometri.

Penelitian sebelumnya menyatakan bahwa ekstrak etanol sambiloto menunjukkan nilai IC $_{50}$ sebesar 792,126 $\mu \mathrm{g} / \mathrm{mL}$ dengan baku standar kuersetin

Eka prasasti nur rachmani dkk... 
yang memiliki nilai $\mathrm{IC}_{50}$ sebesar 3,403 $\mu \mathrm{g} / \mathrm{mL}$ (Rais, 2015). Penelitian yang dilakukan Saranya dkk yaitu menguji aktivitas antioksidan dari isolat andrografolid dari ekstrak sambiloto dan standar asam askorbat. Nilai $\mathrm{IC}_{50}$ dari andrografolid $6 \mu \mathrm{g} / \mathrm{mL}$, tidak jauh berbeda dengan $\mathrm{IC}_{50}$ standar asam askorbat yaitu $5.0 \mu \mathrm{g} / \mathrm{mL}$ (Saranya $\mathrm{dkk}, 2010$ ).Didalam ekstrak dan fraksi dari herba sambiloto terdapat kandungan flavonoid dan andrografolid. Aktivitas antioksidan dari herba sambiloto karena adanya kandungan flavonoid dan andrografolid.

Flavonoid memiliki aktivitas sebagai antioksidan karena sifatnya sebagai akseptor yang baik terhadap radikal bebas, yaitu suatu spesies yang memiliki satu atau lebih elektron tak berpasangan dalam orbitalnya seperti hidroksi radikal dan superoksida yang biasa disebut sebagai ROS (Reactive Oxigen Species) (Sathiskumar et al., 2008).

Aktivitas antioksidan senyawa flavonoid dikarenakan adanya penangkapan radikal bebas melalui donor proton hidrogen dari gugus hidroksil dari flavonoid. Aktivitas antioksidan pada flavonoid dipengaruhi substitusi gugus hidroksi pada posisi orto dan para terhadap gugus $\mathrm{OH}$ dan $\mathrm{OR}$.

Adanya kandungan flavonoid pada herba sambiloto, menyebabkan herba sambiloto memiliki aktivitas antioksidan. Herba sambiloto memiliki potensi yang besar untuk dikembangkan sebagai antioksidan.

\section{KESIMPULAN}

Dari hasil penelitian yang diperoleh maka dapat diambil kesimpulan bahwa fraksi flavonoid bebas andrografolid dari herba sambiloto memiliki aktivitas antioksidan dengan katagori kuat yaitu dengan nilai $\mathrm{IC}_{50}$ sebesar 3,42 $\mu \mathrm{g} / \mathrm{mL}$.

\section{DAFTAR PUSTAKA}

Edy, H.J., Marchaban, Wahyuono, S., dan Nugroho, A.E., 2016. Formulasi Dan Uji Sterilitas Hidrogel Herbal Ekstrak Etanol Daun Tagetes erecta L. Pharmacon, 5: 9-16.

Edy, H.J., Marchaban, Wahyuono, S., dan Nugroho, A.E., 2017. Formulation and Evaluation of Hydrogel Containing Tagetes erecta L. Leaves Etanolic Extract. International Journal of Current Innovation Research, 3: 627-630.

Eka Prasasti Nur Rachmani ${ }^{a}$, Suwijiyo Pramono, and Agung Endro Nugroho. 2016.Total flavonoid content of extract and fractions from andrographis paniculata herbs and its thin layer chromatographic profile.ProceedingBook

International Conference Cardiovascular Diseases Cvd-Ia: Integrated Approach from Basic, Clinical Science, Public Health and

BioethicsScience.Yogyakarta, May 14-17, 2ISBN : 978-9793232-24. Hal 145-152.

Eka Prasasti Nur Rachmani ${ }^{\mathrm{b}}$ dan Tuti Sri Suhesti.2016. Aktivitas antioksidan ekstrak dan fraksi herba sambiloto (Andrographis

Eka prasasti nur rachmani dkk... 
paniculata). Media Pharmaceutica Indonesiana. Vol. 1 No. 2. Hal 100-105.

Hossain, M.S., Urbi, Z., Sule, A., dan Rahman, K.M.H., 2014. Andrographis paniculata (Burm. f.) Wall. ex Nees: A Review of Ethnobotany, Phytochemistry, and Pharmacology. The Scientific World Journal, 2014: 1-28.

Mardawati, E., F. Filianty dan H. Harta. 2008. Kajian Aktivitas Antioksidan Ekstrak Kulit Manggis (Garcinia mangostana L.) dalam Rangka Pemanfaatan Limbah Kulit Manggis di Kecamatan Puspahiang Kabupaten Tasikmalaya. Hal. 4.

Molyneux, P., 2004, The use of the stable free radical diphenylpicrylhydrazyl (DPPH) for estimating antioxidant activity Songklanakarin J. Sci. Technol., 26 (2) : 211-219.

Rais, I.R, 2016, aktivitas antioksidan ekstrak andrographis paniculata, (burm.f.) Ness dengan dua perbedaan penguapan, pharmaciana, vol. 6, no.1, 2016:95-100.

Saranya et al.2010,the antioxidant and $\mathrm{h}^{+} \mathrm{k}^{+}$atpase inhibitory effect of andrographis paniculata and andrographolide in vitro and in vivo studies, pharmacologyonline 1: 356-376.
T. Sathish kumar *, m. Sampath, s. V. Sivachandran, s. Shanmugam and p. Rajasekaran. 2009. Optimal process for the extraction and identification of flavonoids from the leaves of Polyalthia longifolia using L16 Orthogonal design of experiment. Int. J. Biol. Chem. Sci. 3(4): 736-745.

Wahyuningrum, R., Wahyono, D., Mustofa, M., dan Prabandari, Y.S., 2017. A Qualitative Study Discovering the Common Medication-Therapy Problems in Patients with Type 2 Diabetes Mellitus (T2DM) in Indonesia. Asian Journal of Pharmaceutical and Clinical Research, 10: 246. 